\title{
Comparing ethnicity-based and expanded carrier screening methods at a single fertility center reveals significant differences in carrier rates and carrier couple rates
}

\author{
Alexandra Peyser, MD ${ }^{1,2}$, Tomer Singer, MD ${ }^{1,2}$, Christine Mullin, MD ${ }^{1,2}$, Sara L. Bristow, PhD ${ }^{1,2}$, \\ Amber Gamma, $\mathrm{MS}^{3}$, Kenan Onel, MD, $\mathrm{PhD}^{2,3,4}$ and Avner Hershlag, MD ${ }^{1,2}$
}

Purpose: To evaluate the efficiency of expanded carrier screening (ECS) compared with ethnicity-based screening in identifying carriers.

Methods: A total of 4232 infertility patients underwent ECS from a single genetic testing laboratory at our center between June 2013 and July 2015. Self-reported ethnicity was recorded. Carrier rates based on ECS were calculated. In addition, carrier status was determined for two other screening panels: ethnicity-based guidelines or the ECS panel recommended by the American College of Obstetricians and Gynecologists (ACOG) using ECS results. Carrier rate and carrier couple rates were compared in the overall study population and in each self-reported ethnicity.

Results: The ECS panel used to screen the patient population identified 1243 carriers (29.4\%). For the same population, ethnicitybased screening and the ACOG panel would have identified 359 $(8.5 \%)$ and 659 carriers (15.6\%), respectively, representing statistically significant differences. Differences in identifying carriers across self-reported ethnicities varied. In 15 couples (1.2\%), both partners carried pathogenic variants for the same genes, $47 \%$ of whom would have been missed had screening been ethnicity-based.

Conclusion: We propose that all reproductive-aged women should be offered ECS. Carrier couple rates would likely increase further with expansion of the panel, playing a pivotal role in preventing genetic disease in fertility clinics.

Genetics in Medicine (2019) 21:1400-1406; https://doi.org/10.1038/s41436018-0331-y

Keywords: expanded carrier screening; genetics; genetic screening; preimplantation genetic testing

\section{INTRODUCTION}

Traditionally, carrier screening was based on a patient's selfreported ethnicity as recommended by professional societies (Table 1). However, expanded carrier screening (ECS), which forgoes a patient's reported ethnicity, has become increasingly the standard of care for patients seeking fertility treatment. Two main factors have led to recent changes in genetic screening practices: the significant likelihood of missing carriers when screening is limited to ethnicity alone and the development of novel and cost-efficient genomic technologies, making genetic testing more accessible to a greater proportion of individuals. Ethnicity-based screening is often limited by patients' inaccurate self-reporting, or even unawareness, of their ancestry. ${ }^{1}$ Additionally, in-depth studies of isolated ethnic populations revealed intraethnic genetic diversity to be as extensive as interethnic diversity. ${ }^{2}$ The US population is becoming increasingly diverse, with the latest census in 2010 revealing an increase in the proportion of individuals reporting mixed ethnicity. ${ }^{3}$ Therefore, it is not surprising that variants most commonly observed in one ethnicity are frequently found in "unusual suspects"-individuals whose stated or perceived ancestry would not have been expected to carry such variants. ${ }^{4}$ Further, since the Human Genome Project was initiated, new genomic technologies were followed by the rapid development of multigene panels, dramatically increasing accessibility, expediency, accuracy, and cost-efficiency of testing for clinically relevant genetic variants.

As more reproductive medicine providers transition from ethnicity-based screening to ECS, professional societies have published recommendations and guidelines for ECS and for preconception carrier screening in general. An initial policy statement from the American College of Medical Genetics and Genomics (ACMG) in 2013 outlined factors that should

\footnotetext{
${ }^{1}$ Department of Obstetrics and Gynecology, Northwell Health, Division of Reproductive Endocrinology, Manhasset, NY, USA; ${ }^{2}$ Donald and Barbara Zucker School of Medicine at Hofstra/Northwell, Hempstead, NY, USA; ${ }^{3}$ Department of Pediatrics, Northwell Health, Division of Human Genetics and Genomics, Great Neck, NY, USA; ${ }^{4}$ Robert S Boas Center for Genomics and Human Genetics, The Feinstein Institute for Medical Research, Manhasset, NY, USA. Correspondence: Avner Hershlag (Zymania1@northwell.edu)
} 
Table 1 Carrier screening recommendations based on patient ethnicity

\begin{tabular}{|c|c|c|}
\hline Ethnicity & Recommended screening & Reference \\
\hline \multirow[t]{2}{*}{ All women } & Cystic fibrosis & $\begin{array}{l}\text { ACOG, }_{1}^{14} \\
\text { ACMG }^{11}\end{array}$ \\
\hline & Spinal muscular atrophy & $\begin{array}{l}\mathrm{ACOG}_{1}^{14} \\
\mathrm{ACMG}^{13}\end{array}$ \\
\hline $\begin{array}{l}\text { Southern } \\
\text { European }\end{array}$ & $\begin{array}{l}\mathrm{Hb} \beta \text {-chain-related } \\
\text { hemoglobinopathies }\end{array}$ & $\mathrm{ACOG}^{14}$ \\
\hline Hispanic & $\begin{array}{l}\mathrm{Hb} \beta \text {-chain-related } \\
\text { hemoglobinopathies }\end{array}$ & $\mathrm{ACOG}^{14}$ \\
\hline $\begin{array}{l}\text { African } \\
\text { American }\end{array}$ & $\begin{array}{l}\mathrm{Hb} \beta \text {-chain-related } \\
\text { hemoglobinopathies }\end{array}$ & $\mathrm{ACOG}^{14}$ \\
\hline South Asian & $\begin{array}{l}\mathrm{Hb} \beta \text {-chain-related } \\
\text { hemoglobinopathies }\end{array}$ & $\mathrm{ACOG}^{14}$ \\
\hline East Asian & $\begin{array}{l}\mathrm{Hb} \beta \text {-chain-related } \\
\text { hemoglobinopathies }\end{array}$ & $\mathrm{ACOG}^{14}$ \\
\hline Middle Eastern & $\begin{array}{l}\mathrm{Hb} \beta \text {-chain-related } \\
\text { hemoglobinopathies }\end{array}$ & $\mathrm{ACOG}^{14}$ \\
\hline Southeast Asian & $\begin{array}{l}\mathrm{Hb} \beta \text {-chain-related } \\
\text { hemoglobinopathies }\end{array}$ & $\mathrm{ACOG}^{14}$ \\
\hline \multirow{8}{*}{$\begin{array}{l}\text { Ashkenazi } \\
\text { Jewish }\end{array}$} & Bloom syndrome & $\mathrm{ACMG}^{12}$ \\
\hline & Canavan disease & $\begin{array}{l}\mathrm{ACOG}_{1}{ }^{14} \\
\mathrm{ACMG}^{12}\end{array}$ \\
\hline & Familial dysautonomia & $\begin{array}{l}\text { ACOG }_{1}{ }^{14} \\
\text { ACMG }^{12}\end{array}$ \\
\hline & Fanconi anemia group C & $\mathrm{ACMG}^{12}$ \\
\hline & Gaucher disease & $\mathrm{ACMG}^{12}$ \\
\hline & Mucolipidosis IV & $\mathrm{ACMG}^{12}$ \\
\hline & Niemann-Pick type A & $\mathrm{ACMG}^{12}$ \\
\hline & Tay-Sachs disease & $\begin{array}{l}\mathrm{ACOG}^{14} \\
\mathrm{ACMG}^{12}\end{array}$ \\
\hline
\end{tabular}

ACMG American College of Medical Genetics and Genomics, ACOG American College of Obstetricians and Gynecologists.

be considered when designing an ECS panel. ${ }^{5}$ Subsequently, a 2015 joint statement from the ACMG, American Congress of Obstetricians and Gynecologists (ACOG), National Society of Genetic Counselors (NSGC), the Perinatal Quality Foundation, and the Society for Maternal-Fetal Medicine (SMFM) lent further support to ECS. ${ }^{6}$ Most recently, a 2017 ACOG Committee Opinion on carrier screening recommends that obstetricians/gynecologists (OB-GYNs) establish a standard screening approach, concluding that ethnic-specific screening, pan-ethnic screening, and ECS are all acceptable strategies. The committee also commented on the great variability between available ECS platforms, and suggested an ECS panel with 23 disorders that would fit current recommendations for inclusion on such an expanded panel. This panel includes all of the disorders recommended for screening across all ethnicities, and includes a few additional disorders that meet frequency and detection rate criteria.
Previous studies have demonstrated the benefit of ECS compared with ethnicity-based guidelines utilizing different approaches. ${ }^{4,8-10}$ One study calculated carrier rates across 15 ethnic populations and found that many carrier states would not have been identified by ethnicity-based screening. This omission could be due to one of three reasons: first, the disorder was not included in any of the ethnicitybased guidelines; second, the correct ethnicity was not accurately reported; and third, many of the "typical" ethnic variants appear at a much lower frequency in other ethnic groups. ${ }^{4}$ A second study used ECS results from more than 300,000 individuals to model the odds of a child being born with an autosomal recessive or X-linked disorder and found that ethnicity-based screening would have missed carrier couples or carrier females, resulting in a higher chance of an affected child compared with ECS. ${ }^{9,10}$

While these studies demonstrate the benefit of ECS compared with ethnicity-based screening, only a few report the reproductive health-care decisions of carrier couples identified as a result of ECS. ${ }^{11,12}$ In the present study we test the hypothesis that ECS is better than ethnicity-based genetic screening at detecting carriers, thereby improving reproductive health-care options. We calculate the prevalence of carriers and carrier couples in a diverse population of infertility patients seen at a single, largevolume fertility center utilizing a single testing platform and ECS protocol. We determine how many carriers and carrier couples would be identified using ethnicity-based screening recommendations, the ECS panel suggested by ACOG, and an ECS panel offered by a genetic testing laboratory. We also determine the reproductive choices carrier couples make and determine if these couples would have been identified through each of the screening methods. Subsequently, these data are used to determine whether the transition from ethnicity-based screening to ECS is evidence-based.

\section{MATERIALS AND METHODS}

\section{Participants}

Genetic screening results were reviewed retrospectively from female and male patients seen at a single, large academic fertility center between June 2013 and July 2015 at Northwell Health (Manhasset, NY). ECS was offered on an opt-out basis to every new patient during the initial consultation, regardless of whether or not she or he had any prior screening. This included patients seen as couples or as individuals. Concurrent screening was recommended to couples, while sequential screening (female partner first, followed by testing the male if his partner had a positive result) was permitted. Every patient filled out an intake form questionnaire from the ECS vendor to report ethnicity.

All procedures followed were in accordance with the ethical standards of the responsible committee on human experimentation (institutional and national) and with the Helsinki Declaration of 1975 , as revised in 2000. The 
Table 2 Number of carriers detected by ethnicity-based screening or ECS stratified by self-reported ethnicity

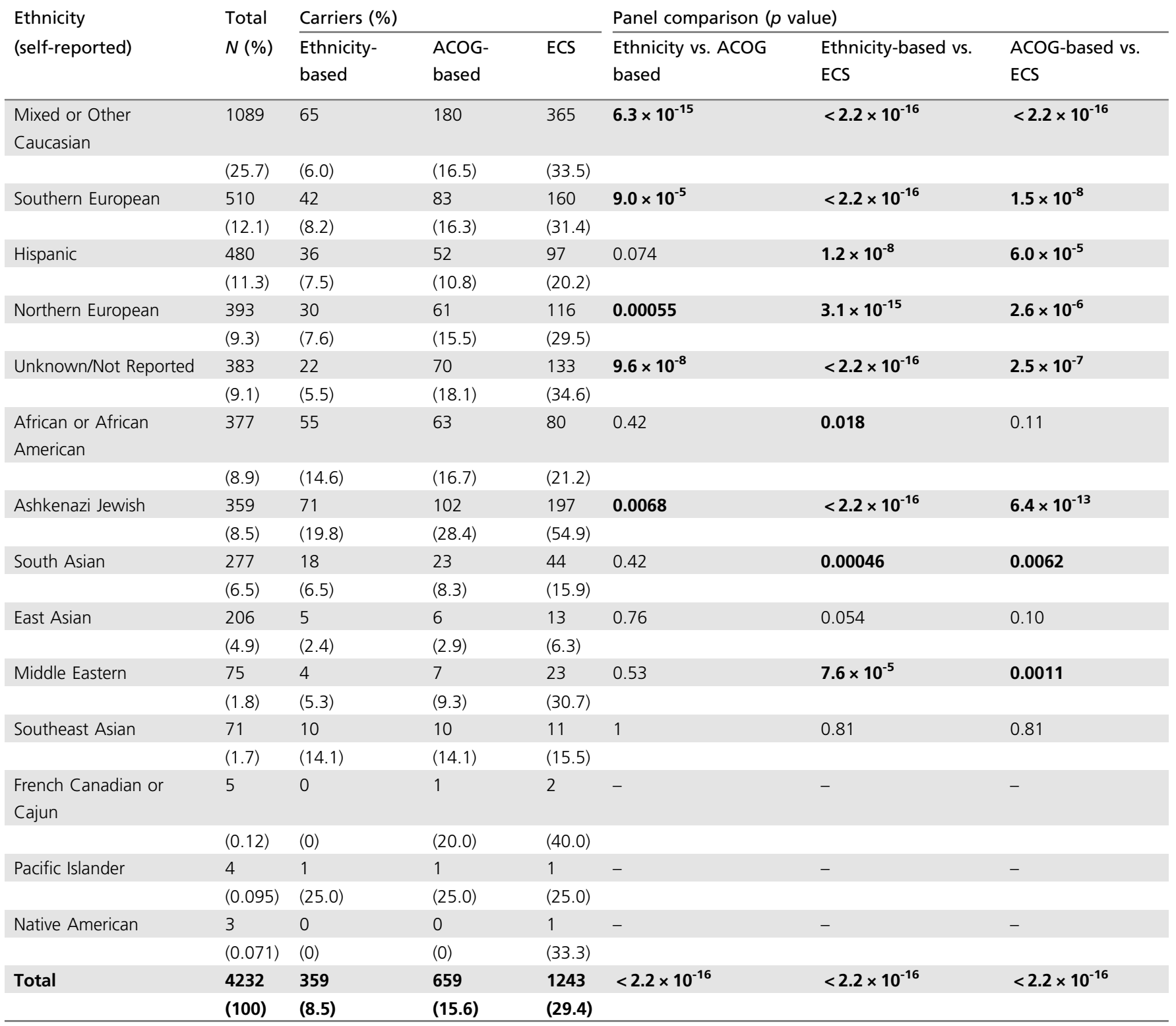

ACOG American College of Obstetricians and Gynecologists; ECS expanded carrier screening. Bold entries demonstrate $p$ values of $\leq 0.05$

Northwell Health Institutional Review Board reviewed and approved this study. Informed consent was obtained from all study participants.

\section{Genetic testing}

Blood samples from each patient were tested via genotyping for clinically significant pathogenic variants using an ECS panel from a single genetic testing laboratory. The panel is comprised of 400 variants of 102 genes, associated with 100 genetic diseases (Counsyl, San Francisco, CA). ${ }^{9,10}$ In addition to these single-base substitutions, the panel also determined the size of the CGG repeats in the 5' UTR of $F M R 1$ to screen for fragile $\mathrm{X}$ syndrome, as well as SMN1 exon 7 copy-number status to screen for spinal muscular atrophy.

\section{Identifying carriers using ethnicity-based guidelines and ECS panels}

All subjects included in the study underwent ECS from the genetic testing laboratory. For each patient, carrier status (carrier or noncarrier) was determined based on three panels: ethnicity-based screening (Table 1), ACOG-recommended ECS panel (ACOG-based screening), and commercial ECS panel used at our center. ${ }^{13-16}$ Differences between the three panels are listed in Supplement 1. Carrier rates were calculated for the overall study population and for each ethnic subpopulation and then compared to determine differences between carrier pickup rates by each panel. It is important to note that the ECS panel did not screen for $\alpha$ thalassemia and maple syrup urine disease 1A (MSUD1A), which are two conditions included in the ACOG-based 
screening panel. Therefore, the carrier rate for the ACOGbased screening was calculated without including these two conditions.

\section{Data analysis}

Summary statistics including median and average age, gender breakdown, and ethnicity breakdown were calculated.

Chi-square test or Fisher's exact tests (for sample sets with frequencies $\leq 5$ ) were applied to determine differences in numbers of carriers identified. Three comparisons were made: (1) ethnicity-based screening versus ACOG-based screening, (2) ethnicity-based screening versus ECS, and (3) ACOGbased screening versus ECS. The analysis was performed on the overall study population and in ethnic subpopulations with more than 50 individuals.

We defined "carrier couples" as couples found to be carriers of deleterious pathogenic variants in the same gene, and calculated the number of carrier couples that would have been identified by an ethnicity-based screening panel as compared with ECS, using a chi-square test to assess significance of this comparison. We performed a chart review to investigate whether carrier couples or females with X-linked disorders elected to have embryos resulting from in vitro fertilization (IVF) tested for the identified disorder through preimplantation genetic testing (PGT).

A $p$ value cutoff of $p \leq 0.05$ was considered significant in all cases. All analyses were performed using R (v 3.3.3). ${ }^{17}$

\section{RESULTS}

A total of 4232 infertility patients were tested using the ECS panel from the genetic testing laboratory (2880 females [68.1\%]; 1352 males [31.9\%]). The median age of the patients screened was 35.7 years (overall mean $35.9 \pm 5.6$ years; males $=37.4 \pm 6.4$, females $=35.1 \pm 5.0$ ). Of the 4232 patients tested, $359(8.5 \%)$ would have been identified as carriers if tested according to ethnicity-based screening recommendations (Table 2). Had the ACOG sample ECS panel (ACOGbased screening) been used, 659 carriers (15.6\%) would have been identified, an additional 300 carriers compared with the ethnicity-based methods. In contrast, 1243 (29.4\%) patients were recognized as carriers using the full ECS panel (Table 2). The differences in carrier rates between each panel were highly significant (Table 2).

We compared the carrier frequencies between each panel in the overall study population and in subpopulations based on self-reported ethnicity. When the three panels were compared, the number of detected individuals increased with increasing panel size across the overall study population and in all but 3 of 14 self-reported ethnicities (Table 2). In two ethnic populations (Southeast Asian and Native American), only the increase from ACOG-based screening to ECS resulted in additional carriers. The number of carriers in the Pacific Islander population did not increase regardless of the panel. Statistical comparisons between the panels were conducted for the overall study population and the 11 ethnic populations with greater than 50 individuals (Table 2). In the
Table 3 Clinical characteristics of carrier couples

\begin{tabular}{|c|c|c|c|}
\hline Couple & Disease & $\begin{array}{l}\text { Ethnicity } \\
\text { (female } \\
\text { partner) }\end{array}$ & $\begin{array}{l}\text { Ethnicity } \\
\text { (male } \\
\text { partner) }\end{array}$ \\
\hline 1 & $\begin{array}{l}\text { Hb } \beta \text {-chain-related } \\
\text { hemoglobinopathy }\end{array}$ & $\begin{array}{l}\text { African or } \\
\text { African } \\
\text { American }\end{array}$ & $\begin{array}{l}\text { African or } \\
\text { African } \\
\text { American }\end{array}$ \\
\hline 2 & Achromatopsia $^{a}$ & South Asian & South Asian \\
\hline 3 & $\begin{array}{l}\text { GJB2-related DFNB1 } \\
\text { nonsyndromic hearing loss } \\
\text { and deafness }{ }^{a}\end{array}$ & $\begin{array}{l}\text { Northern } \\
\text { European }\end{array}$ & $\begin{array}{l}\text { Northern } \\
\text { European }\end{array}$ \\
\hline 4 & $\begin{array}{l}\mathrm{Hb} \beta \text {-chain-related } \\
\text { hemoglobinopathy }\end{array}$ & $\begin{array}{l}\text { African or } \\
\text { African } \\
\text { American }\end{array}$ & $\begin{array}{l}\text { African or } \\
\text { African } \\
\text { American }\end{array}$ \\
\hline 5 & $\alpha-1$ antitrypsin deficiency ${ }^{a}$ & $\begin{array}{l}\text { Northern } \\
\text { European }\end{array}$ & $\begin{array}{l}\text { Unknown/ } \\
\text { Not } \\
\text { Reported }\end{array}$ \\
\hline 6 & $\begin{array}{l}\mathrm{Hb} \beta \text {-chain-related } \\
\text { hemoglobinopathy }\end{array}$ & $\begin{array}{l}\text { African or } \\
\text { African } \\
\text { American }\end{array}$ & $\begin{array}{l}\text { African or } \\
\text { African } \\
\text { American }\end{array}$ \\
\hline 7 & Cystic fibrosis & $\begin{array}{l}\text { Mixed or } \\
\text { Other } \\
\text { Caucasian }\end{array}$ & $\begin{array}{l}\text { Southern } \\
\text { European }\end{array}$ \\
\hline 8 & Gaucher disease & $\begin{array}{l}\text { Ashkenazi } \\
\text { Jewish }\end{array}$ & $\begin{array}{l}\text { Ashkenazi } \\
\text { Jewish }\end{array}$ \\
\hline 9 & Familial Mediterranean fever ${ }^{a}$ & $\begin{array}{l}\text { Southern } \\
\text { European }\end{array}$ & $\begin{array}{l}\text { Ashkenazi } \\
\text { Jewish }\end{array}$ \\
\hline 10 & Pompe disease $\mathrm{e}^{\mathrm{a}}$ & $\begin{array}{l}\text { Northern } \\
\text { European }\end{array}$ & $\begin{array}{l}\text { Mixed or } \\
\text { Other } \\
\text { Caucasian }\end{array}$ \\
\hline 11 & Smith-Lemli-Opitz syndrome ${ }^{a}$ & $\begin{array}{l}\text { Northern } \\
\text { European }\end{array}$ & $\begin{array}{l}\text { Ashkenazi } \\
\text { Jewish }\end{array}$ \\
\hline 12 & Pompe disease ${ }^{a}$ & $\begin{array}{l}\text { Southern } \\
\text { European }\end{array}$ & $\begin{array}{l}\text { Unknown/ } \\
\text { Not } \\
\text { Reported }\end{array}$ \\
\hline 13 & Spinal muscular atrophy & $\begin{array}{l}\text { Northern } \\
\text { European }\end{array}$ & $\begin{array}{l}\text { Mixed or } \\
\text { Other } \\
\text { Caucasian }\end{array}$ \\
\hline 14 & Cystic fibrosis & $\begin{array}{l}\text { Southeast } \\
\text { Asian }\end{array}$ & $\begin{array}{l}\text { Southeast } \\
\text { Asian }\end{array}$ \\
\hline 15 & Familial dysautonomia & $\begin{array}{l}\text { Ashkenazi } \\
\text { Jewish }\end{array}$ & $\begin{array}{l}\text { Ashkenazi } \\
\text { Jewish }\end{array}$ \\
\hline
\end{tabular}

${ }^{a}$ Indicates these couples would have been missed by ethnic based screening.

overall population and five subpopulations, frequencies in carrier rates were statistically different in all three pairwise comparisons: Mixed or Other Caucasian, Southern European, Northern European, Unknown/Not Reported, and Ashkenazi Jewish. In three subpopulations (Hispanic, South Asian, and Middle Eastern), significant differences were observed in the ethnicity-based screening versus ECS and ACOG-based screening versus ECS, but not the ethnicity-based screening versus ACOG-based screening comparison. The African or African American population only demonstrated significant 
differences when comparing ethnicity-based screening versus ECS. In two ethnic populations (East Asian and Southeast Asian), none of the carrier frequencies for each panel were statistically different.

A total of 1206 couples were screened using the ECS panel. Of these, 15 couples (1.2\%) were carrier couples. Table 3 lists the disorders diagnosed in these 15 couples as well as the ethnicity of each partner. Eight of the 15 couples would have been identified through ethnicity-based screening guidelines. All 15 carrier couples elected to screen embryos using PGT to transfer an unaffected embryo. In addition to the carrier couples, 73 women were identified as carriers for fragile X. As fragile $\mathrm{X}$ is caused by the expansion of a three-nucleotide repeat in the FMR1 gene, carriers for fragile $\mathrm{X}$ include those with the intermediate expansion, the premutation, and the full expansion. Of the 73 carriers, 53 women carried the intermediate expansion, one of whom pursued PGT; 17 carried the premutation, two of whom pursued PGT; and 2 women carried the full expansion; however, they did not follow up to our center for care.

\section{DISCUSSION}

While prenatal screening, including carrier screening and aneuploidy screening, is recommended in early to midpregnancy, carrier screening is frequently omitted in routine gynecological care for women of reproductive age. At fertility centers, however, carrier screening is performed at an increasing frequency prior to fertility treatment, thus providing patients with additional choices when planning a pregnancy. Another recent trend among fertility centers is the transition from ethnicity-based carrier screening to ECS. Such panels typically include a large number of variants, irrespective of whether they have been observed within the patient's stated ethnicity. While many variants included in the panel are of high-penetrance and/or are deleterious, a number of variants have a variable penetrance pattern and may not severely affect quality of life. While this study focused on results from a genotyping platform, newer sequencing technologies are able to identify many more variants that lead to even further increased carrier and carrier couple rates. In addition, patients are screened regardless of past personal or family history of a genetic disease. Parallel to this diagnostic evolution, there has been a significant refinement of IVF-PGT technology, allowing for the detection and selection of unaffected embryos prior to embryo transfer.

In this study, we demonstrate that ECS screening from the genetic screening laboratory is superior to both ethnicitybased screening and the ACOG-based screening panel in diagnosing carrier status across multiple ethnicities. In three ethnic populations, the increase in carrier screening panel size from ethnicity-based recommendations to the ACOG-based screening did not significantly increase the number of carriers (Hispanic; South Asian; Middle Eastern), suggesting that the ACOG-based screening panel does not add clinically meaningful disorders for these populations. Across all screening methods, ethnicity-based screening identified essentially all the carriers within the East Asian and Southeast Asian populations, as demonstrated by the nonsignificant differences observed when comparing panels. This observation may be due to a small sample size, although it may also be that the diseases and/or variants included in either ECS panel are uncommon in East Asians and Southeast Asians relative to other populations. This is also the case for other ethnic groups in our study population not included in the statistical analysis, including Pacific Islanders.

Given the rapid advances in genomic technologies and in our (still incomplete) understanding of human genetics, ECS has become a more attractive screening method to provide patients with as much information as possible, thus empowering them to make prepregnancy decisions that will impact the health of their offspring. Over the years, guidelines from professional societies and available ethnicity-based panels have been modified to "catch up" with genetic disorders previously not included. In a way this has been a hindsight approach, because recommendations are based on limited population-based data, often with a focus on Caucasian populations and limited data for other ethnicities. This outcome argues that screening for more diseases may be beneficial for patients planning a pregnancy, even if population carrier frequencies and/or detection rates are unknown. Indeed, a recent survey of medical professionals, including physicians and genetic counselors, demonstrated that a majority of providers (77\%) would prefer to screen for more disorders as compared with fewer. ${ }^{17}$ Additional advantages to ECS have also been debated and described elsewhere, highlighting the benefits of this screening method for couples planning to become pregnant. ${ }^{18,19}$

The frequency of carrier couples in our study was $1.2 \%$ (15 of 1206 couples), all of whom underwent IVF with PGT. All cycles resulted in unaffected pregnancies. Had ethnicity-based screening been applied, almost half of these couples (47\%) would have gone undiagnosed and would stand the risk of having an affected child. Hence, ECS utilization holds the promise of providing patients with more reproductive options and greater control over outcomes. Other studies have investigated the impact of ECS on screening outcomes in a variety of patient settings. One of the original studies that summarized the carrier rates of a very large study population found a carrier rate of $24 \%$, where at least $69 \%$ of those carriers carried variants for disorders not included in the ethnicity-based screening recommendations. ${ }^{4}$ That study also discussed the number (not percent) of carrier couples. Another study characterizing the implementation of ECS found the carrier couple rate to be only $0.21 \%$. ${ }^{11}$ The study used three screening panels from two different companies, two different testing protocols, and three different screening protocols. Differences in carrier couple rates may have resulted from differences in the screening methodologies, the number of variants tested, or differences in the ethnic backgrounds of the patient populations served at each fertility center, as it is well documented that carrier rates differ greatly between ethnicities. 
Of the 17 patients with the fragile $\mathrm{X}$ premutation, 7 had undergone intrauterine insemination (IUI), 1 used timed intercourse, 4 did not have follow up, and 5 used IVF. Of the five that underwent IVF, only two elected to undergo PGT for fragile $\mathrm{X}$. The two patients with the full expansion did not return for care, and it is unknown whether they sought treatment elsewhere.

It is of interest that while patients affected with fragile $\mathrm{X}$ premutation or full expansion were reluctant to undergo PGT, all 15 carrier-carrier couples for other genes pursued PGT. All those who carried the premutation were offered prenatal testing or PGT, because it is the most effective way to stop the expansion of the CGG repeats in future generations. Fragile $\mathrm{X}$ remains the most common cause of inherited intellectual disability. Even when the risk of expansion is low based on the number of AGG interruptions, premutation carriers are still at risk for premature ovarian failure (POF) and fragile $\mathrm{X}$-associated tremor/ataxia syndrome (FXTAS), where PGT can be helpful.

Patients who had opted not to go for PGT had several reasons, including cost, the increased complexity and stress involved, and perhaps the disbelief (despite genetic counseling) that their child is at risk. Patients with a full fragile $\mathrm{X}$ expansion may themselves have intellectual disabilities and may have a hard time interpreting the information given to them through counseling. ${ }^{20} \mathrm{~A}$ study that analyzed PGT results of fragile X carriers noted that there was a lack of fertility decline awareness in those with the premutation. ${ }^{21}$ Based on these findings, it is important that the full impact of the fragile $\mathrm{X}$ carrier state be explained through genetic counseling, and a sharp distinction drawn between the impact of fragile $\mathrm{X}$ versus autosomal recessive gene pathogenic variants.

When carrier couples at risk for an affected child are identified prior to conception, they should be counseled about all of their reproductive options including that IVF coupled with PGT is the only preconception method likely to prevent the birth of an affected biological child. While this technology continues to evolve, it requires high-level expertise in the lab; because PGT is often not covered by insurance, it can be a quite expensive investment for the couple. Other alternatives include the use of donor gametes or embryos, adoption, or early prenatal diagnostic testing. ${ }^{22}$ While these alternatives may seem simpler, and in some instances cheaper (donor sperm but not donor eggs), patients may have a hard time parting with their own genome. We feel that the addition of ECS to our practice has fortified our preconception testing and improved pregnancy outcomes.

While most patients present to our center for infertility, another subset presents due to having either a child or a terminated fetus affected by a genetic disorder that the parents had been unaware of carrying prior to conception. In many cases, the variant would have been discovered by ECS. Further, the couple does not have the chance to pursue IVF paired with PGT for this pregnancy. Genetic counseling can aid couples in making an informed decision that is best for them. This highlights the need to broaden the use of ECS to primary care and OB-GYN practices to increase access to all reproductive options for all couples.

During the study period, we recommended ECS to all patients, including those who had ethnicity-based panels. Less than $10 \%$ of all new patients opted out of ECS, most of the time because of lack of insurance coverage or because they had previous genetic testing by other panels. A limitation to our study is that within our population are patients who seek ECS due to a family history of a specific disorder. This may raise the rate of carrier couples found in the study. In addition, patients diagnosed with recurrent pregnancy loss have been found to be carriers of certain conditions such as Smith-Lemli-Opitz syndrome and congenital disorder of glycosolation type 1a, which could have skewed the results. ${ }^{23}$ Another limitation is the lack of detection of variants for those of less common ethnic backgrounds who did not receive the benefit of extensive research on their carrier status. In addition, some diseases may have late onset as well as variable phenotypes, which can increase patient anxiety and cause confusion.

The detection of carriers for each of the genes tested is dependent on the design of the test, which in turn is related to the number of variants tested and the frequency among the various ethnicities. While ECS attempts to override the ethnic differences, clearly the ability to detect variants for each gene depends on the population tested. While the population at our center is diverse and multiethnic, it would be difficult to apply our findings globally or nationally given the vastly different ethnic mix.

This study represents our patient population, which is unique and inherently different from other geographic areas, and may vary widely in ethnic and genetic mix. Carrier rates of various disorders are expected to change in different patient populations. In addition, genetic screening panels continue to expand both in breadth (more genes) and depth (more variants). The discovery of a carrier status is thus limited to the specific platform used at our center during the time period studied. In all likelihood, further expanded ECS should yield a higher carrier couple rate.

\section{Conclusions}

In summary, we present evidence that ECS is superior to ethnicity-based genetic screening at detecting disease carriers and carrier couples. While ACOG has taken a neutral position in genetic screening recommendations, we believe that our study provides additional evidence that ECS offers the richest amount of preconception information for patients. While ECS is increasingly offered to patients by reproductive endocrinologists, it is still inconsistently utilized in other settings. This may be due to the perceived cost of testing, insurance coverage, reproductive beliefs, timing, or patient's lack of interest in receiving this sort of information. However, our data suggest that expanded ECS coupled with genetic counseling may benefit all women and men contemplating a pregnancy. 


\section{ELECTRONIC SUPPLEMENTARY MATERIAL}

The online version of this article (https://doi.org/10.1038/s41436018-0331-y) contains supplementary material, which is available to authorized users.

\section{DISCLOSURE}

The authors declare no conflicts of interest.

\section{REFERENCES}

1. Nazareth SB, Lazarin GA, Goldberg JD. Changing trends in carrier screening for genetic disease in the United States. Prenat Diagn. 2015:35:931-5.

2. Moreno-Estrada A, Gignoux CR, Fernández-López JC, et al. Human genetics. The genetics of Mexico recapitulates Native American substructure and affects biomedical traits. Science. 2014;344:1280-5.

3. US Census Bureau. Statistical abstract of the United States: 2011. 130th ed. Washington, D.C.; 2010.

4. Lazarin GA, Haque IS, Nazareth $S$, et al. An empirical estimate of carrier frequencies for $400+$ causal Mendelian variants: results from an ethnically diverse clinical sample of 23,453 individuals. Genet Med. 2013;15:178-86.

5. Grody WW, Thompson BH, Gregg AR, et al. ACMG position statement on prenatal/preconception expanded carrier screening. Genet Med. 2013;15:482-3.

6. Edwards JG, Feldman G, Goldberg J, et al. Expanded carrier screening in reproductive medicine-points to consider. Obstet Gynecol 2015;125:653-62.

7. American College of Obstetricians and Gynecologists. Committee opinion no. 690. Obstet Gynecol. 2017;129:e35-e40.

8. Shraga R, Yarnall S, Elango S, et al. Evaluating genetic ancestry and selfreported ethnicity in the context of carrier screening. BMC Genet. 2018:18:99

9. Haque IS, Lazarin GA, Kang HP, Evans EA, Goldberg JD, Wapner RJ. Modeled fetal risk of genetic diseases identified by expanded carrier screening. JAMA. 2016;316:734.
10. Srinivasan BS, Evans EA, Flannick J, et al. A universal carrier test for the long tail of Mendelian disease. Reprod Biomed Online. 2010;21:537-51.

11. Franasiak JM, Olcha M, Bergh PA, et al. Expanded carrier screening in an infertile population: how often is clinical decision making affected? Genet Med. 2016;18:1097-101.

12. Ghiossi C, Goldberg J, Haque I, et al. Clinical utility of expanded carrier screening: reproductive behaviors of at-risk couples. J Genet Couns. 2018;3:616-25.

13. Watson MS, Cutting GR, Desnick RJ, et al. Cystic fibrosis population carrier screening: 2004 revision of American College of Medical Genetics mutation panel. Genet Med. 2004;6:387-91.

14. Gross SJ, Pletcher BA, Monaghan KG. Carrier screening in individuals of Ashkenazi Jewish descent. Genet Med. 2008;10:54-6.

15. Prior TW. Carrier screening for spinal muscular atrophy. Genet Med. 2008; 10:840-2.

16. American College of Obstetricians and Gynecologists. Committee opinion no. 691. Obstet Gynecol. 2017;129:e41-55.

17. R Core Team. R: a language and environment for statistical computing. 2017.

18. Ready K, Haque IS, Srinivasan BS, Marshall JR. Knowledge and attitudes regarding expanded genetic carrier screening among women's healthcare providers. Fertil Steril. 2012;97:407-13.

19. van der Hout S, Holtkamp KC, Henneman L, de Wert G, Dondorp WJ. Advantages of expanded universal carrier screening: what is at stake? Eur J Hum Genet. 2017;25:17-21.

20. Lubs HA, Stevenson RE, Schwartz CE. Fragile $X$ and $X$-linked intellectual disability: four decades of discovery. Am J Hum Genet. 2012;90:579-90.

21. Tsafrir A, Altarescu G, Margalioth E, et al. PGD for fragile X syndrome: ovarian function is the main determinant of success. Hum Reprod. 2010:25:2629-36.

22. Metcalfe SA. Carrier screening in preconception consultation in primary care. J Community Genet. 2012;3:193-203.

23. Scott R, Franasiak JM Embryo and endometrial synchrony in implantation failure. In: Recurrent implantation failure: etiologies and clinical management. Franasiak, JM, Scott Jr RT (eds). Springer: Switzerland. 2018:80-2. 